\title{
Tingkat Risiko Psikologis Karyawan ATC di Salah Satu Cabang Air NAV Indonesia
}

\section{Psychological Risk Level of Air Traffic Controllers in Air NAV Indonesia}

\author{
Lalu Muhammad Saleh ${ }^{*}$, Syamsiar S. Russeng ${ }^{1}$, Hasanduddin Ishak ${ }^{2}$ \\ ${ }^{1}$ Departemen Keselamatan dan Kesehatan Kerja FKM Universitas Hasanuddin \\ ${ }^{2}$ Departemen Kesahatan Lingkungan FKM Universitas Hasanuddin \\ (*lalums@unhas.ac.id)
}

\begin{abstract}
ABSTRAK
Air Traffic Controller (ATC) adalah profesi yang bertugas sebagai pemandu lalu lintas udara yang memiliki tingkat stres tinggi dalam bekerja. ATC bekerja mengedepankan otak sehingga beban mental dapat terjadi. Penelitian bertujuan melihat sejauh mana tingkat risiko psikologis yang dihadapi ATC dalam bekerja dan jenis hazard yang menjadi penyebab. Sampel penelitian adalah karyawan ATC di Makassar Air Traffic Service Centre yang berjumlah 35 orang. Pengumpulan data dengan menggunakan kuesioner dan pengukuran risiko menggunakan matriks penilaian risiko menurut standar AS/NZS 4360. Hasil penelitian menunjukkan bahwa tingkat risiko paling tinggi yang dapat memengaruhi aspek psikologis dalam bekerja adalah karena pola kerja 3 hari kerja 1 hari istirahat, kurangnya jumlah teman dalam bekerja, jumlah pesawat yang diamati, suhu yang dingin. Kesimpulan penelitian adalah karyawan ATC mengalami risiko psikologis karena beratnya pola kerja 3-1, jumlah teman yang kurang, jumlah pesawat yang banyak, dan suhu yang dingin.
\end{abstract}

Katakunci : ATC, tingkat risiko, psikologis, Air NAV

\section{ABSTRACT}

Air Traffic Controller (ATC) is a profession that serves as an air traffic guide who has a high level of stress in work. ATC works put forward the brain so that mental burden can occur. This study aims to see how far the level of psychological risk factor ATC in work and hazard what causes it. The sample of research is ATC employees in Makassar Air Traffic Service Center which amounted to 35 people. Data collection using questionnaire and risk measurement using risk assessment matrix according to AS/NZS 4360 standard. The results showed that the highest level of risk that could affect the psychological aspects in work is due to work patterns 3 working days 1 rest day, the lack of number of friends in work, number of planes observed, cold temperatures. The conclusion of the study was that ATC employees had psychological risks due to the work pattern 3-1, lack of friends, large numbers of aircraft, and cold temperatures. It is advisable to the management to immediately increase the amount of ATC power, and provide work clothes as a protector of cold temperatures.

Keywords : ATC, risk level, psychological, Air NAV 


\section{PENDAHULUAN}

Penerbangan global akhir-akhir ini mengalami peningkatan dari jumlah armada maupun jumlah penumpang. Keadaan yang sama terjadi pada industri penerbangan di Indonesia yang mengalami kemajuan dalam 10 tahun terakhir. Menurut International Air Transport Association (IATA) Indonesia memiliki potensi yang sangat besar dalam sektor penerbangan, diestimasikan bahwa pada tahun 2034 Indonesia akan mampu menjadi 6 (enam) pasar terbesar dalam air travel di dunia, diekspektasikan terdapat sekitar 270 juta penumpang yang akan terbang melakukan perjalanan domestik, maupun internasional ataupun hanya melewati lintas udara negara Indonesia. Olehnya IATA meminta kepada para pemangku kepentingan penerbangan di Indonesia untuk merencanakan segala prioritas utama baik keamanan, kapasitas, dan peraturan. ${ }^{1}$

Lancarnya penerbangan sudah tentu tidak lepas dari berbagai peran para pemandu lalu lintas udara atau air traffic controller yang mengatur, memantau, dan menginformasikan segala bentuk yang berhubungan dengan fluensi penerbangan. Namun, tidak dapat dipungkiri, perhatian akan aspek keselamatan dan kesehatan kerja karyawan Air Traffic Controller (ATC) harus menjadi perhatian penting, agar produktivitas tetap optimal untuk dapat memandu lalu lintas udara. Konsentrasi optimal dalam memandu pilot mengemudikan pesawat harus selalu dimiliki oleh petugas ATC, tetapi kelelahan kerja tetap dapat terjadi sewaktuwaktu pada controller jika tidak memperhatikan keselamatan dan kesehatan kerja. Kelelahan psikologis merupakan aspek yang sering terjadi pada karyawan ATC berupa kejenuhan, stres, dan burnout. Kelelahan merupakan suatu yang inevitable dalam sektor kerja yang periode kerjanya berlangsung $24 \mathrm{jam} / 7$ hari dikarenakan fungsi otak dan tubuh manusia yang optimal tidak tidur dengan baik dimalam hari ${ }^{2}$ diketahui bahwa jam operasional sektor penerbangan hampir bekerja mencapai waktu 24 jam/7 hari sekalipun dalam manajemen waktu ATC dilakukan waktu kerja per shift (pagi, siang, dan malam). Menurut International Civil Aviation Organization (ICAO), shift work tetap berkontribusi atas terjadinya gangguan psikologis pada ATC berupa stress karena dapat mengganggu waktu tidur dan mempengaruhi hubungan sosial para pekerja, kemudian boredom yang dikaitkan dengan kurangnya aktivitas pekerja, dan burnout yang dihubungkan dengan workload. ${ }^{3}$

Peraturan Direktur Jenderal Perhubungan Udara Nomor KP 218 Tahun 2017 menetapkan jumlah jam kerja personal pemandu lalu lintas penerbangan yakni, jam pemanduan dalam 1 minggu tidak lebih dari 24 (dua puluh empat) jam. Jumlah jam pemanduan dalam 1 hari tidak lebih dari 6 (enam) jam, dengan ketentuan pemanduan paling lama dilakukan selama 2 jam berturut-turut, dan harus diberikan jeda waktu istirahat selama 1 jam. ${ }^{4}$ Sehingga, jika ketentuan ini tidak diaplikasikan sebagaimana mestinya tingkat kelelahan kerja akan terjadi.

Terkait kelelahan kerja pada ATC di Indonesia diketahui berkisar $92 \%$ yang mengalami perasaan lelah, dengan kelelahan kerja yang terjadi dapat berdampak pada munculnya gangguan atau bahaya dalam penerbangan sehingga memicu timbulnya produktivitas kerja menurun. Dampak lain adalah kemungkinan terjadinya kecelakaan pesawat atas faktor kelelahan petugas ATC. Kinerja yang baik dari karyawan ATC akan mendukung keselamatan penerbangan, dan penerbangan yang selamat akan menyelamatkan jutaan jiwa nyawa penumpang dalam setiap harinya. Olehnya kesehatan dan keselamatan kerja dari karyawan ATC harus selalu menjadi salah satu prioritas untuk mendapatkan kinerja yang optimal. Penelitian bertujuan mengetahui tingkat risiko psikologis karyawan Air Traffic Controller, dengan melihat faktor yang paling mempengaruhi terjadinya risiko psikologis tersebut.

\section{BAHAN DAN METODE}

Jenis penelitian adalah penelitian kuantitatif dengan desain cross sectional study, lokasi penelitian di laksanakan di Makassar Air Traffic Service Centre, Bandara Internasional Sultan Hasanuddin dan waktu penelitian dilaksanakan pada bulan Agustus 2017, populasi penelitian adalah seluruh karyawan Air Traffic Controller (ATC) dan sampel penelitian adalah sebanyak 35 orang responden, teknik sampling dengan accidental sampling. Pendekatan teknik accidental sampling merupakan jenis non-probability sampling yang paling mudah untuk memenuhi jumlah sampel penelitian 
dan subyektif. ${ }^{5-7}$ Teknik pengumpulan data dilakukan secara primer dengan mengumpulkan data secara langsung kepada responden menggunakan kuesioner, analisis data dengan analisis univariat, dan penyajian data menggunakan tabel dan narasi. Metode dalam menganalisis tingkat risiko dilakukan dengan menggunakan standar AS/NZS 4360.

\section{HASIL}

Hasil penelitian menunjukkan bahwa karakteristik karyawan ATC menjelaskan tentang jenis kelamin, umur, tingkat pendidikan, masa kerja, shift kerja, lama istirahat, dan unit kerja yang dapat dijelaskan pada Tabel 1 yang menunjukkan bahwa karyawan ATC yang tertinggi pada jenis kelamin laki-laki sebanyak 29 orang $(82,9 \%)$, umur ter- tinggi pada umur 20-29 tahun sebanyak 20 orang $(57,1 \%)$, tingkat pendidikan tertinggi pada tingkat pendidikan Diploma Tiga (D3) 27 orang $(77,1 \%)$, masa kerja tertinggi adalah masa

Tabel 1. Karakteristik Karyawan Air NAV Indonesia Cabang Makassar

\begin{tabular}{lcc}
\hline \multicolumn{1}{c}{ Karakteristik } & $\mathbf{n}$ & $\mathbf{\%}$ \\
\hline Jenis Kelamin & 29 & 82,9 \\
Laki-laki & 6 & 17,1 \\
Perempuan & & \\
Umur (tahun) & 20 & 57,1 \\
20-29 & 8 & 22,9 \\
30-39 & 4 & 11,4 \\
40-49 & 3 & 8,6 \\
50-59 & & \\
Tingkat Pendidikan & 27 & 77,1 \\
D3 & 7 & 20,0 \\
D4/S1 & 1 & 2,9 \\
S2 & & \\
Masa Kerja & 25 & 71,4 \\
Lama & 10 & 28,6 \\
Baru & & \\
Shift Kerja & 7 & 20,0 \\
Pagi & 26 & 74,3 \\
Siang & 2 & 5,7 \\
Malam & & \\
Jam Istirahat (menit) & 10 & 28,6 \\
0-60 & 14 & 40,0 \\
61-120 & 11 & 31,4 \\
121-180 & & \\
Unit Kerja & 21 & 60,0 \\
ADC & 13 & 37,1 \\
APP & & \\
ACC & & \\
\hline & & \\
& &
\end{tabular}

kerja lama sebanyak 25 orang $(71,4)$, shift kerja tertinggi pada shift kerja siang sebanyak 26 orang (74,3\%), jam istirahat tertinggi 61-120 menit sebanyak 14 orang $(40 \%)$, dan unit kerja tertinggi pada unit Aerodrome Control Unit (ADC) sebanyak 21 orang $(60 \%)$.

Tabel 2 menjelaskan tentang tingkat risiko pada karyawan Air NAV cabang Makassar yang tertinggi adalah pada tingkat risiko rendah karena hubungan antar karyawan ATC sebanyak 97,1\%, pada tingkat risiko sedang tertinggi adalah ritme kerja pola 3 hari kerja 1 hari istirahat, lama kerja 2-3 jam/shift, dan jumlah pesawat yang diamati, pada tingkat risiko tinggi tertinggi adalah karena ritme kerja pola 3 hari kerja 1 hari istirahat, dan tingkat risiko extreme tertinggi adalah peralatan dan fasilitas kerja dan bertugas pada cuaca buruk sebanyak 5,7\%.

Berdasarkan hasil Tabel 2 memperlihatkan bahwa tingkat risiko extreme tertinggi karena peralatan dan fasilitas kerja dan bertugas pada cuaca buruk. Tingkat risiko tinggi karena ritme kerja pola 3 hari kerja 1 hari istirahat, tingkat risiko sedang tertinggi karena ritme kerja pola 3 hari kerja 1 hari istirahat, lama kerja 2-3 jam/shift, jumlah pesawat yang diamati. Tingkat risiko rendah yang tertinggi karena hubungan dengan pimpinan.

\section{PEMBAHASAN}

Penelitian menemukan hasil bahwa tingkat risiko tertinggi pada risiko extreme karena keadaan fasilitas kerja dan bertugas saat cuaca buruk, tingkat risiko tinggi terbanyak karena pola kerja 3-1 yaitu 3 hari bekerja dengan 1 hari istirahat. Hasil ini memperlihatkan bahwa kondisi fasilitas kerja dan bertugas saat cuaca buruk memberikan pengaruh yang besar terhadap kerja sebagai controller, di samping itu adalah karena pola kerja 3-1 sangat berat dirasakan oleh karyawan ATC. Penelitian ini semakin memperkuat bukti yang telah dikemukakan International Civil Aviation Organization (ICAO) bahwa peralatan kerja yang tidak memadai merupakan salah satu faktor yang dapat memicu munculnya gangguan psikologis berupa stres pada pengendali lalu lintas udara olehnya ICAO menyarankan untuk mengeluarkan pekerja untuk sementara dan jika tuntutan waktu ATC untuk pekerjaan tertentu dirasakan berlebihan maka beban kerja tersebut harus dikurangi dengan me- 
Tabel 2. Tingkat Risiko Karyawan Air NAV Cabang Makassar

\begin{tabular}{|c|c|c|c|c|c|c|c|c|}
\hline \multirow{3}{*}{ Uraian } & \multicolumn{8}{|c|}{ Tingkat Risiko } \\
\hline & \multicolumn{2}{|c|}{ Rendah } & \multicolumn{2}{|c|}{ Sedang } & \multicolumn{2}{|c|}{ Tinggi } & \multicolumn{2}{|c|}{ Extreme } \\
\hline & $\mathbf{n}$ & $\%$ & $\mathbf{n}$ & $\%$ & $\mathbf{n}$ & $\%$ & $\mathbf{n}$ & $\%$ \\
\hline Ritme Kerja Pola 3 hari kerja 1 hari istirahat & 12 & 34,3 & 10 & 28,6 & 13 & 37,1 & & \\
\hline Lama Kerja 2-3 jam/shift & 18 & 51,4 & 10 & 28,6 & 7 & 20,0 & & \\
\hline Jumlah pesawat yang diamati & 15 & 42,9 & 10 & 28,6 & 10 & 28,6 & & \\
\hline Kurangnya jumlah teman kerja & 14 & 40,0 & 9 & 25,7 & 11 & 31,4 & 1 & 2,9 \\
\hline Shift kerja harian & 19 & 54,3 & 7 & 20,0 & 8 & 22,9 & 1 & 2,9 \\
\hline Hubungan antar karyawan ATC & 34 & 97,1 & 1 & 2,9 & & & & \\
\hline Hubungan dengan pimpinan & 33 & 94,3 & 2 & 5,7 & & & & \\
\hline Pencahayaan yang kurang & 26 & 74,3 & 6 & 17,1 & 2 & 5,7 & 1 & 2,9 \\
\hline Iklim kerja yang tidak sehat & 21 & 60,0 & 6 & 17,1 & 7 & 20,0 & 1 & 2,9 \\
\hline Suhu & 19 & 54,3 & 6 & 17,1 & 10 & 28,6 & & \\
\hline Kelembaban & 34 & 97,1 & 1 & 2,9 & & & & \\
\hline Peralatan dan Fasilitas Kerja & 22 & 62,9 & 7 & 20,0 & 4 & 11,4 & 2 & 5,7 \\
\hline Bertugas saat cuaca buruk & 18 & 51,4 & 7 & 20,0 & 8 & 22,9 & 2 & 5,7 \\
\hline Permasalahan Internal keluarga & 30 & 85,7 & 3 & 8,6 & 1 & 2,9 & & \\
\hline
\end{tabular}

rancang ulang tugas dan mengalokasikan kembali tanggung jawab yang sesuai. ${ }^{8}$ Penelitian Widodo et al., terkait tingkat stres pemandu lalu lintas udara menemukan bahwa ada hubungan yang kuat antara tingkat stres kerja dengan kinerja petugas ATC Jakarta. Hasil analisis statistik dalam persamaan regresi menemukan $\hat{Y}=90,86-0,785 X$ atau diartikan bahwa bahwa tiap satu satuan kenaikan tingkat stres kerja petugas, maka akan mempengaruhi penurunan kinerja petugas pemandu lalu lintas penerbangan sebesar 0.785 dalam satuan konstanta $90.86 .^{9}$

Hasil kajian literatur King et al., terkait pengetahuan dan kemampuan ATC pada weather dalam penerbangan menemukan bahwa masih terdapatnya petugas ATC yang pemahaman dasar meteorologinya masih kurang, masih kurangnya pelatihan terkait skenario cuaca, berbagai peralatan dan informasi terkait kondisi cuaca spesifik pada daerah yang dilintasi pesawat masih terbatas, Existing Protocol, dan kesalahpahaman dalam koordinasi antar pilot dan ATC. ${ }^{10}$ Segala bentuk masalah yang ditemukan tersebut menjadikan acuan agar tercipta rencana keselamatan penerbangan yang lebih ditingkatkan lagi. Kemudian penelitian Budiman et al., di bandara Angkasa Pura II Indonesia menemukan rata-rata beban kerja seluruh petugas ATC diklasifikasikan atas beban mental yang tinggi disebabkan peak hours biasanya terjadi pada shift siang dan shift pagi, dan untuk shift malam dikaitkan dengan operator ATC yang harus menuntun pilot dengan kondisi jarak pandang pilot yang pendek pada suasana gelap $^{11}$, hal ini sejalan dengan temuan Åkerstedt and Wright, shift kerja malam juga memiliki efek negatif terkait siklus tidur, mampu menyebabkan kantuk, kinerja dan berisiko terhadap terjadinya kecelakaan. ${ }^{12}$ Kemudian temuan Zużewicz, et al., terkait shift work ditemukan bahwa ketika jadwal penerbangan padat dalam suatu shift work maka ritme sikardian tubuh controller juga akan berubah atau Heart Rate Variability (HRV) akan berpengaruh. ${ }^{13}$ Padahal diketahui bahwa ketika jadwal tugas berturut-turut dilaksanakan oleh petugas ATC maka dapat mengakibatkan gangguan tidur atau tidur yang terbatas, sehingga individu dinyatakan memiliki hutang waktu tidur dan kemungkinan juga akan mengalami gangguan psikologis berupa peningkatan kelelahan, dan sebagai solusinya ialah individu atau petugas membutuhkan minimal dua malam penuh tidur secara berturutturut atau berdasarkan akumulasi hutang tidur untuk memulihkan kondisinya. ${ }^{2}$

Menurut Simon Ashley Bennet Direktur Unit Sipil Keselamatan dan Keamanan (CSSU) University of Leicester telah menemukan fakta bahwa beberapa faktor yang berkontribusi terjadinya kecelakaan pesawat yakni kesalahan pilot $(50 \%)$, kegagalan teknik $(20 \%)$, cuaca $(10 \%)$ sekalipun telah dibantu menggunakan peralatan berupa 
kompas, gyroscopic, navigasi satelit, dan uplink data cuaca, pesawat masih tidak dapat menghalau badai, salju, dan kabut. Kemudian terdapat faktor sabotase (sambaran petir) yang menyumbang berkisar $10 \%$, serta kesalahan manusia itu sendiri, dalam hal ini dikaitkan dengan kesalahan pada air traffic controller dan beberapa pihak terkait (dispatcher, loader, pengisi bahan bakar, atau teknisi pemeliharaan). Adapun peran Air Traffic Controller dikaitkan dengan shift panjang petugas ${ }^{14}$ yang dapat menyebabkan kelelahan.

Penelitian yang di laksanakan Antoško M, et al., dalam pengujian kesiapan psikologis oleh ATC diketahui bahwa subjek yang diteliti mencapai kinerja maksimal setiap hari hanya dalam dua jam pengujian. Hilangnya konsentrasi dan berkurangnya kinerja kerja terjadi setelah delapan jam dan mencapai nilai kritis setelah dua belas jam pengujian. Kurva rasio kesalahan menunjukkan kecenderungan naik. Oleh karena itu, dapat diasumsikan bahwa semakin lama petugas diteliti maka akan memburuk pengujian. Perlu diketahui bahwa subjek dalam penelitian ini tidak terlibat dalam kegiatan yang menantang, yang akan hadir dalam operasi nyata, studi ini lebih menekankan pada konsentrasi dan perhatian yang besar. ${ }^{15} \mathrm{Se}-$ hingga dapat ditarik kesimpulan bahwa jika seorang controller yang dalam keadaan pengujian atau pelatihan diberikan beban kerja rendah, tetapi berkesinambungan akan mengalami gangguan psikologis, maka sudah tentu gangguan psikologis dan kesalahan mungkin akan terjadi kepada petugas ATC jika petugas tersebut dihadapkan langsung dengan suatu yang real pada periode kerja yang berlangsung lama.

Hal ini dapat disimpulkan bahwa petugas yang memiliki shift kerja panjang atau kapasitas kerja tidak memadai dapat berkontribusi dalam munculnya kelelahan psikologis dan kejadian yang tidak diinginkan baik pada petugas ATC maupun pada pelayanan pesawat terlebih jika fasilitas yang digunakan tidak mendukung kelancaran kerja dan sedang menghadapi kondisi cuaca yang buruk. Cuaca yang buruk bisa menyebabkan dampak buruk dalam dunia penerbangan dan dapat mengakibatkan kecelakaan yang disebabkan oleh cuaca yaitu turbulensi, icing, dan kilat turbulensi. Turbulensi adalah golakan udara yang umumnya tidak dapat dilihat. Penyebab terjadinya turbulen- si adalah suhu, jet stream, pegunungan, dan wake turbulence. ${ }^{16}$

Berdasarkan hasil ini memperlihatkan bahwa pola kerja 3-1 harus segera dirubah oleh pihak manajemen Air NAV sehingga akan memberikan waktu istirahat yang cukup buat karyawan. Hal lainnya adalah bertugas pada saat cuaca buruk harus dilakukan upaya pencegahan agar tidak mengalami tekanan yang berat buat karyawan ATC. Fasilitas yang rusak harus segera diperbaiki agar tidak menambah beban kerja ATC.

Permasalahan yang dihadapi oleh karyawan ATC harus disadari agar dapat dicegah dan tidak memberikan risiko yang lebih berat kedepannya. Langkah-langkah yang harus ditempuh manajemen Air NAV harus menjalankan aturan waktu cuti 34 hari sesuai Peraturan Direktur Jenderal Perhubungan Udara Nomor SKEP/17/II/2009 Tanggal 13 Pebruari 2009. Waktu cuti 12-16 hari setahun harus dirubah dan mengikuti aturan dirjen perhubungan udara yang mewajibkan 34 hari dalam setahun. Solusi lainnya adalah semua peralatan dan fasilitas yang rusak harus cepat diperbaiki atau jika memungkinkan fasilitas terkait kerja harus segera diganti dengan teknologi yang memadai agar tidak menambah risiko bahaya penerbangan.

Penerbangan Indonesia akan menjadi lebih baik dan memiliki kualitas yang optimal jika semua elemen dalam penerbangan bekerja secara optimal dan berkualitas. Karyawan ATC memiliki tingkat risiko psikologis seperti stres, jenuh, dan burnout. Risiko yang dialami oleh karyawan ATC tersebut harus dikelola sehingga tidak menimbulkan kelelahan psikologis yang lebih berat. Faktor manusia dalam dunia penerbangan mempunyai andil paling besar dalam terjadinya kecelakaan yaitu $66 \%{ }^{16}$

Tingkat kemajuan suatu bangsa dalam penerbangan dilihat dari penerapan kebijakan keamanan dan keselamatan penerbangan dari negaranya. Sistem Manajemen Keselamatan (Safety Management System) merupakan bentuk upaya dari perusahaan penerbangan dalam memonitor kegiatan penerbangan agar dapat diciptakan keselamatan dalam penerbangan. SMS adalah suatu sistem monitoring yang berupa tim atau organisasi di dalam suatu perusahaan penerbangan yang memiliki tugas dan tanggung jawab serta memoni- 
tor kinerja keselamatan dari perawatan dan pengoperasian serta memprediksi suatu bahaya, menganalisis risiko dan melakukan tindakan pengurangan risiko. ${ }^{16}$

\section{KESIMPULAN DAN SARAN}

Kesimpulan penelitian menunjukkan bahwa tingkat risiko extreme tertinggi karena peralatan dan fasilitas kerja dan bertugas pada cuaca buruk, tingkat risiko tinggi adalah pola kerja ritme 3 hari kerja 1 hari istirahat, lama kerja 2-3 jam/shift, dan jumlah pesawat yang diamati, dan tingkat risiko rendah tertinggi adalah hubungan antar karyawan. Manajemen diharapkan untuk merubah pola kerja 3-1 menjadi 3-2, menambah jumlah tenaga ATC, dan perbaikan fasilitas yang rusak.

\section{UCAPAN TERIMA KASIH}

Ucapan terima kasih diberikan kepada 1) Kementerian Pendidikan Tinggi Indonesia 2) General Manajer Air Nav Cabang MATSC dan Manajer Safety Management System 3) Karyawan Air Traffic Controller (ATC) khususnya di Makassar.

\section{DAFTAR PUSTAKA}

1. International Air Transport Association (IATA). Developing the Potential of Indonesia's Aviation Sector 2015. Available from: http://www.iata.org/pressroom/pr/Pages/2015-03-12-01.aspx.

2. Margison G. Fatigue Management Guide for Air Traffic Service Providers. Kanada; 2016.

3. ICAO. Human Factors Training Manual. ICAO, Montreal. Canada; 1993.

4. Peraturan Direktur Jenderal Perhubungan Udara. Peraturan Direktur Jenderal Perhubungan Udara Nomor: Kp 218 Tahun 2017 Tentang Perubahan Atas Peraturan Direktur Jenderal Perhubungan Udara Nomor Kp 287 Tahun 2015 Tentang Pedoman Teknis Operasional Bagian 69-01 (Advisory Circular Part 69-01) Tentang Lisensi, Rating, Pelatihan dan Kecakapan Personel Pemandu Lalu Lintas Penerbangan. In: Udara KPDJP, editor. Jakarta.

5. Saryono, Anggraeni MD. Metode Penelitian Kualitatif dan Kuantitatif. Yogyakarta: Nuha Medika; 2013.
6. Hasmi. Metode Penelitian Epidemiologi. Trans Info Media: Jakarta; 2012.

7. Notoatmodjo S. Metode Penelitian Kesehatan. Rineka Cipta: Jakarta; 2010.

8. International Civil Aviation Organization (ICAO). Human Factors Digest No. 8-Human Factors in Air Traffic Control. ICAO, Montreal. Canada; 1993.

9. Widodo ES, Fahmi R, Pantaryanto N. Tingkat Stres Petugas Pemandu Lalu Lintas Penerbangan. Jurnal Manajemen Bisnis Transportasi dan Logistik. 2015;2(1):64-81.

10. King JM, Ortiz Y, Blickensderfer BL, editors. ATC Weather Knowledge \& Skills: A Contributor to the General Aviation Weather Problem? Proceedings of the Human Factors and Ergonomics Society Annual Meeting; 2016: SAGE Publications Sage CA: Los Angeles, CA.

11. Budiman J, Pujangkoro S, Kes AM. Analisis Beban Kerja Operator Air Traffic Control Bandara Xyz dengan Menggunakan Metode Nasa-Tlx. Jurnal Teknik Industri USU. 2013;3(3).

12. Åkerstedt T, Wright KP. Sleep loss and Fatigue in Shift Work and Shift Work Disorder. Sleep medicine clinics. 2009;4(2):257-71.

13. Zużewicz K, Kwarecki K, Waterhouse J. Circadian Rhythm of Heart Rate, Urinary Cortisol Excretion, and Sleep in Civil Air Traffic Controllers. International Journal of Occupational Safety and Ergonomics. 2000;6(3):383-92.

14. Khoiri A. Lima Faktor Penyebab Terjadinya Kecelakaan Pesawat Jakarta: CNN Indonesia; 2016. Available from: https://www.cnnindonesia.com/gaya-hidup/20160524100733-269-133019/lima-faktor-penyebab-terjadinya-kecelakaan-pesawat/.

15. Antoško M, Pil'a J, Korba P. Psychological Readiness of Air Tra ffic Controllers for their Job. NAŠE MORE, Znanstveno-stručni časopis za more i pomorstvo. 2014;61(1-2):S5-8.

16. Gunaryadi, dkk, Keselamatan Penerbangan, Tinjauan Keselamatan Penerbangan Sipil di Indonesia, Mitra Wacana Media. Jakarta; 2016. 